ORIGINAL ARTICLE

\title{
Obtaining high cure rates for challenging facial malignancies: A new method for producing rapid, accurate, high-quality frozen sections
}

\author{
Kirsty Boyd MD ${ }^{1,2}$, Colin Henderson BSc MLT ${ }^{3,4}$, Mariamma Joseph MD FRCPC ${ }^{5}$, \\ Nick Yardley MD ${ }^{1}$, Claire Temple MD MSc FRCSC $1,2,4$
}

K Boyd, C Henderson, M Joseph, N Yardley, C Temple. Obtaining high cure rates for challenging facial malignancies: A new method for producing rapid, accurate, high-quality frozen sections. Can J Plast Surg 2011;19(1):22-26.

PURPOSE: The authors developed a new system to provide rapid, accurate, full-face frozen sections.

OBJECTIVE: To evaluate the efficacy of the system when applied to the treatment of nonmelanoma cutaneous malignancies using Mohs micrographic surgery (MMS).

METHODS: Patients undergoing MMS procedures between 2003 and 2007 for nonmelanoma head and neck cutaneous malignancies were prospectively collected. Specimens were prepared either in a traditional cryostat-based manner or using the new system.

RESULTS: A total of 196 patients with 234 head and neck nonmelanoma cutaneous malignancies were included. The majority of tumours were basal cell carcinomas (89.5\%). Of these, 38\% demonstrated aggressive histologies (sclerosing or micronodular), and 30\% were recurrent. On average, two levels (range one to six) and four blocks (range two to 23) were required to obtain clear margins. The mean defect size was $3.68 \mathrm{~cm}^{2}$ (range $0.13 \mathrm{~cm}^{2}$ to $37.68 \mathrm{~cm}^{2}$ ). Over the five-year study period, there were two recurrences in 234 cases (less than 1\%), which compares favourably with other MMS series. The new system was associated with a shorter operative time than traditional specimen preparation (102 min versus $131 \mathrm{~min} ; \mathrm{P}=0.004$ ). The new and traditional specimen preparation groups were similar in terms of the number of previous recurrences ( $29 \%$ versus $30 \% ; \mathrm{P}=1.00)$, defect size $\left(3.7 \mathrm{~cm}^{2}\right.$ versus $4.0 \mathrm{~cm}^{2} ; \mathrm{P}=0.81$ ) and the number of levels required (1.9 versus 1.5; $\mathrm{P}=0.05)$.

CONCLUSIONS: The new system enables fast, accurate, full-face frozen section specimens that are ideal for MMS. The speed of specimen preparation is demonstrated by faster operative times, and a low recurrence rate attests the accuracy and quality of the sections.

Key Words: Conforming plane; CryoCaddy; Disposable base mold embedding; Mohs micrographic surgery; Platform mold
L'obtention de taux de guérison élevés pour des tumeurs malignes faciales complexes :

une nouvelle méthode pour produire rapidement des coupes d'échantillons congelés précises et de qualité

BUT : Les auteurs ont mis au point un nouveau système pour obtenir rapidement des coupes complètes et précises d'échantillons congelés. OBJECTIF : Évaluer l'efficacité du système lorsqu'il est appliqué au traitement de tumeurs malignes cutanées non mélaniques au moyen de la chirurgie micrographique de Mohs (CMM).

MÉTHODOLOGIE : Les chercheurs ont colligé prospectivement les données sur les patients qui ont subi une CMM entre 2003 et 2007 en raison de tumeurs malignes cutanées non mélaniques de la tête et du cou. Ils ont préparé des échantillons soit par coupe classique au cryostat, soit au moyen du nouveau système.

RÉSULTATS : Au total, 196 patients ayant 234 tumeurs malignes non mélaniques de la tête et du cou ont participé à l'étude. La majorité des tumeurs prenaient la forme de carcinomes basocellulaires (89,5\%). De ce nombre, $38 \%$ avaient des histologies agressives (sclérosantes ou micronodulaires), et $30 \%$ étaient récurrentes. En moyenne, il fallait deux couches (de une à six) et quatre blocs (de deux à 23) pour obtenir des marges saines. La dimension moyenne des anomalies était de $3,68 \mathrm{~cm}^{2}$ (plage de $0,13 \mathrm{~cm}^{2}$ à $37,68 \mathrm{~cm}^{2}$ ). Pendant la période d'étude de cinq ans, on a constaté deux récurrences sur 234 cas (moins de $1 \%$ ), ce qui se compare favorablement aux autres séries de CMM. Le nouveau système s'associait à une durée d'opération moins longue qu'en cas de préparation de l'échantillon classique (102 minutes par rapport à $131 ; \mathrm{P}=0,004)$. Les groupes de préparation d'échantillons nouveau et classique étaient similaires pour ce qui est du nombre d'occurrences précédentes ( $29 \%$ par rapport à $30 \% ; \mathrm{P}=1,00)$, de la dimension des anomalies $\left(3,7 \mathrm{~cm}^{2}\right.$ par rapport à $\left.4,0 \mathrm{~cm}^{2} ; \mathrm{P}=0,81\right)$ et du nombre de couches nécessaires ( 1,9 par rapport à 1,$5 ; \mathrm{P}=0,05)$.

CONCLUSIONS : Le nouveau système permet d'obtenir rapidement des coupes complètes et précises d'échantillons congelés, idéales pour la CMM. La vitesse de préparation des échantillons est démontrée par la diminution de la durée d'opération, et le faible taux de récurrences atteste de la précision et de la qualité des coupes.

The purpose of the present study was to evaluate the efficacy of our system as applied to the treatment of nonmelanoma cutaneous malignancies using MMS.

\section{METHODS}

Patient recruitment

Consecutive patients presenting to the senior author for MMS with biopsy-proven, nonmelanoma, head and neck cutaneous malignancies were prospectively studied over a five-year period. Indications for MMS included aggressive histology, difficult anatomical sites, multiple recurrent lesions and large tumours. The study received approval from the tation technique are required (Figure 1).

${ }^{1}$ Schulich School of Medicine; ${ }^{2}$ Division of Plastic Surgery, University of Western Ontario; ${ }^{3}$ London Laboratory Services Group; ${ }^{4}$ Lawson Health Research Institute; ${ }^{5}$ Department of Pathology, University of Western Ontario, London, Ontario

Correspondence: Dr Claire Temple, Department of Surgery, Division of Plastic Surgery, St Joseph's Health Care, 268 Grosvenor Street, London, Ontario N6A 4L6. Telephone 519-646-6389, fax 519-646-6049, e-mail ctemple4@uwo.ca 

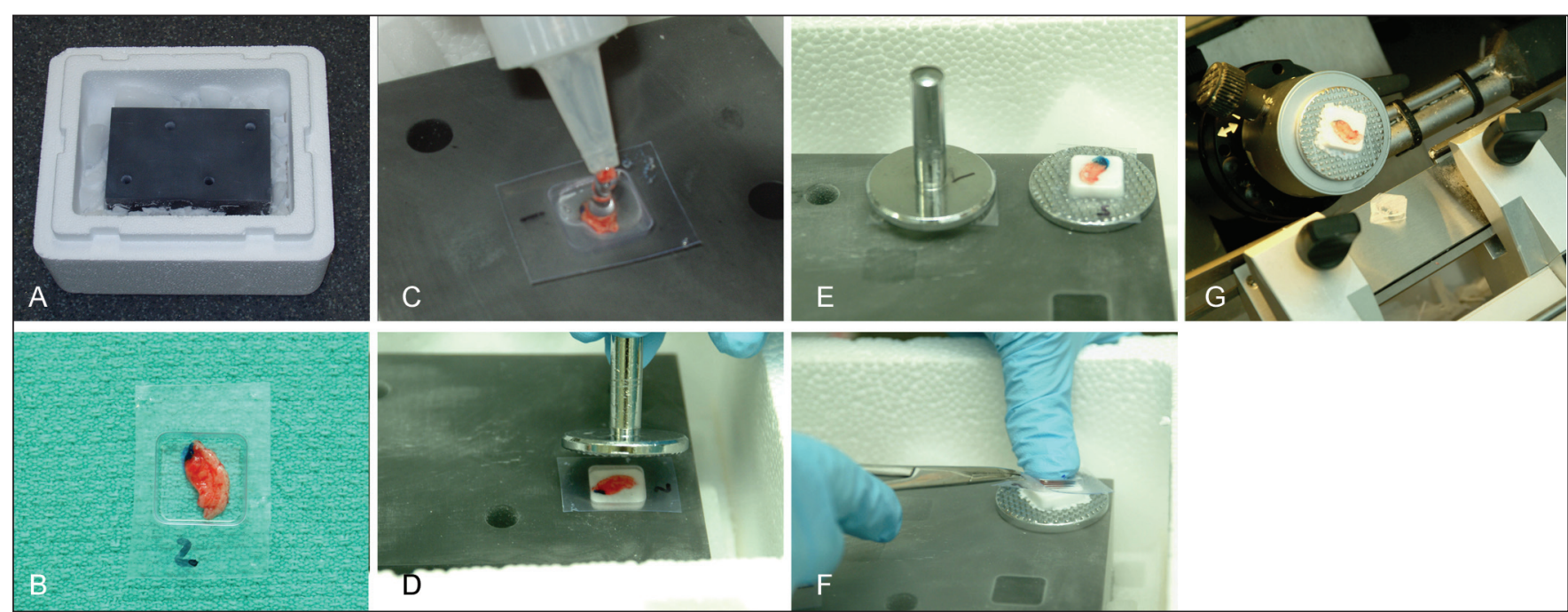

Figure 1) A The CryoCaddy consists of an aluminum block set into an insulated box and surrounded with dry ice. Chuck postholes have been drilled into the block to permit inversion of the chuck (top left). B The peripheral and deep margins of the specimen are pressed into the same plane on the bottom of the platform mold. The semitransparent plastic allows direct visualization to confirm that the margin is completely flat. C The tissue freezing compound is added to the platform mold, which is slightly overfilled. D A room temperature chuck is pressed onto the meniscus of the tissue freezing compound before freezing is complete. $\mathrm{E}$ Once the base has started to freeze and the true margin is anchored, the chuck is inverted and the stem is placed into a posthole. F Once freezing is complete, the platform mold is peeled from the block. G The accurately oriented specimen is presented to the microtome blade. Reproduced with permission from the Journal of Histotechnology

University of Western Ontario (London, Ontario) health sciences research ethics board $(\# 16752 \mathrm{E})$.

\section{Traditional versus new technique for specimen preparation}

The traditional method involved a two-step process of orienting and freezing the margin first, and then joining this frozen construct to a chuck. The first step involved laying the deep margin against the surface of a glass microscope slide. The tissue was then covered in the tissue freezing compound (TFC) and frozen in a cryostat chamber at $-20^{\circ} \mathrm{C}$, which was a relatively slow process. In the second step, the frozen TFC 'button' was separated from the glass slide, inverted and refrozen onto a microtome chuck.

The traditional technique did allow precise orientation of the deep resection margin in one plane; however, second-stage refreezing of the TFC 'button' introduced variations between the tissue and microtome cutting planes. These variations required either time-consuming adjustment of the microtome (cutting plane) or, for expediency, trimming through the true deep margin to expose a full-face section. Excess trimming risked the possibility of exposing residual tumour that was deep to the resection margin, resulting in a false-positive margin, and requiring an additional unnecessary MMS level.

In the new one-stage technique, specimen freezing and chuck attachment occurred at the same time. Freezing occurred outside the cryostat chamber, using a heat sink housed in an insulated Styrofoam (The Dow Chemical Company, USA) chamber, that was cooled to $-78^{\circ} \mathrm{C}$ (CryoCaddy) with dry ice (Figure 1 ). The specimen was oriented in a clear, disposable base mold. Relaxing scalpel cuts were made as necessary to allow the skin edge to lie in the same plane as the deep surface. Visual confirmation that the true margin was flush with the mold was obtained through a semitransparent surface. The mold was slightly overfilled with TFC (Tissue-Tek OCT Compound, Sakura Finetek, USA) and placed on the freezing platform. The TFC solidified, anchoring the specimen in place. A chuck was then pressed onto the overfilled meniscus of the TFC, inverted and inserted into one of the chuck postholes in the aluminum block to facilitate cooling. When freezing was complete, the mold was peeled off with a hemostat and the block was transferred to the cryostat
(Leica CM 3050S, Leica Microsystems Inc, USA) for sectioning. The parallel plane relationship between the block face and cutting plane of the microtome was consistently maintained with the new technique.

\section{Surgical details}

There were several differences in the treatment of this series of patients when compared with 'traditional' MMS practice. First, patients underwent MMS in a main operating theatre and received conscious sedation. In addition, a small minority (2\%) of these patients who required procedures exceeding $2.5 \mathrm{~h}$ were treated with general anesthesia. Finally, patients underwent resection with frozen section control and definitive reconstruction during a single operative session.

MMS specimens were harvested as per standard technique, using the scalpel held at a $45^{\circ}$ angle to the skin, with a complete peripheral and deep margin excised for evaluation. The surgeon transported the specimens to the frozen section room and prepared the tissue for en face sectioning in either the traditional or the new method. Slides were stained with hematoxylin and eosin, reviewed for the presence of tumour and mapped for any positive margins. Additional tissue was removed in the areas of positivity, and the process was repeated until the peripheral and deep margins were free of tumour. A clinical example of MMS is provided in Figure 2.

Details of the original pathology, previous methods of treatment and method of reconstruction were obtained. Specifics of the MMS procedure, including total operative time (surgical start to end time), number of levels, number of blocks and defect size, were recorded.

\section{Statistical analysis}

Statistical analysis was performed using InStat 3 version $3.0 \mathrm{~b}$ (GraphPad Software Inc, USA) for Macintosh (Apple Inc, USA). The Student's $t$ test and $\chi^{2}$ test were used to compare the traditional and new technique groups for continuous outcomes and proportions, respectively. $\mathrm{P}<0.05$ was considered to be statistically significant. A Kaplan-Meier survival curve was used to determine recurrence-free survival at five years. 

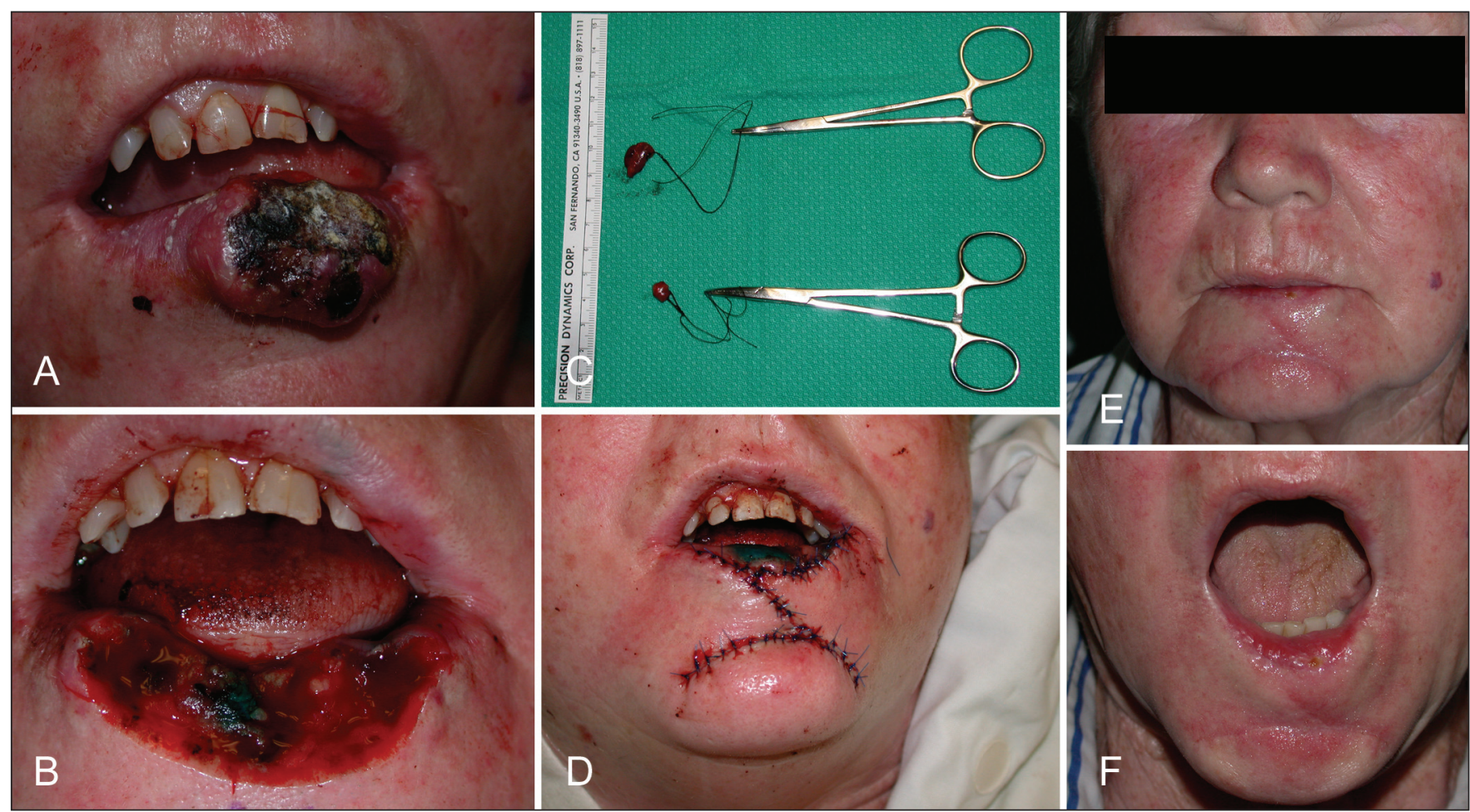

Figure 2) A Rapidly enlarging squamous cell carcinoma of the lower lip. B A $7.85 \mathrm{~cm}^{2}$ defect following Mohs micrographic surgery, which required two levels and six blocks to clear. C Two sentinel nodes were negative. D, E and F Early postoperative results showing preserved oral function following reconstruction

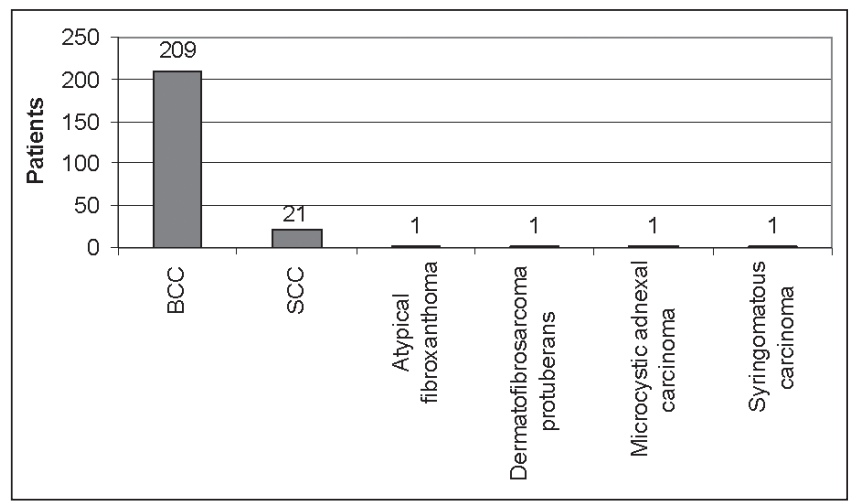

Figure 3) Type of lesion according to biopsy-proven pathology. BCC Basal cell carcinoma; SCC Squamous cell carcinoma

\section{RESULTS}

\section{Patient demographics}

There were 234 nonmelanoma head and neck cutaneous malignancies in 196 patients included in the study. The average patient age was 66 years at the time of surgical resection (range 34 to 95 years); $56 \%$ of patients were female. Follow-up averaged 28 months (range 10 days to 63 months).

\section{Lesion characteristics}

Of the 234 lesions included in the study, $89.5 \%$ were basal cell carcinomas (Figure 3). Other pathological subtypes included squamous cell carcinoma (9\%), atypical fibroxanthoma $(0.5 \%)$, dermatofibrosarcoma protuberans $(0.5 \%)$, syringomatous carcinoma $(0.5 \%)$ and microcystic adnexal carcinoma $(0.5 \%)$. Aggressive histology (sclerosing and micronodular) was present in $38 \%$ of basal cell carcinomas (Figure 4). Sixty-eight (30\%) of the lesions were recurrent.

Ninety-four $(40 \%)$ of the lesions were located on the nose, $40(18 \%)$ on the forehead/temple and $35(15 \%)$ on the cheek. Other locations included perioral $(n=11)$, periorbital $(n=10)$, ear $(n=9)$, chin $(n=9)$, scalp $(n=6)$ and neck $(n=5)$.

\section{Surgical details}

On average, two levels (range one to six) and four blocks (range two to 23) were required to obtain negative margins. Twenty-three specimens were prepared in the traditional manner, and 211 using the new system. The mean defect size was $3.68 \mathrm{~cm}^{2}$ (range $0.13 \mathrm{~cm}^{2}$ to $\left.37.68 \mathrm{~cm}^{2}\right)$. One-third of the lesions were associated with a defect size larger than $3.1 \mathrm{~cm}^{2}$.

\section{Method of reconstruction}

Reconstruction required flap coverage in $78 \%$ of lesions, the majority of which were local. Skin grafts were used in $9 \%$ and primary closure in $7 \%$ of lesions.

\section{Recurrence}

Despite the challenging histologies, facial locations and recurrent nature of the lesions, recurrence-free survival at five years was 98.5\% (Figure 5). There were two local recurrences in 234 cases. The first was in a 42-year-old woman with a triple recurrent and previously radiated sclerosing basal cell carcinoma on her temple (Figure 6). She underwent MMS; it took four levels and 23 blocks to clear her tumour. Her defect size measured $50 \mathrm{~cm}^{2}$. She required a free latissimus dorsi flap for reconstruction. At 24 months post-MMS, she developed periorbital recurrence requiring orbital exenteration and free flap reconstruction. She died six months later of an initially undiagnosed multiple myeloma. The second recurrence was in a 61-year-old woman referred with a fivetime recurrent sclerosing basal cell carcinoma of her upper lip. Using MMS, her tumour took four levels and eight blocks to clear, leaving her with a $14 \mathrm{~cm}^{2}$ defect. The carcinoma recurred at 28 months, and she underwent repeat MMS. She is currently recurrence free at 13 months.

\section{Operative time}

The new system decreased the time of frozen section preparation, thereby reducing the start-to-finish time for each MMS case by 


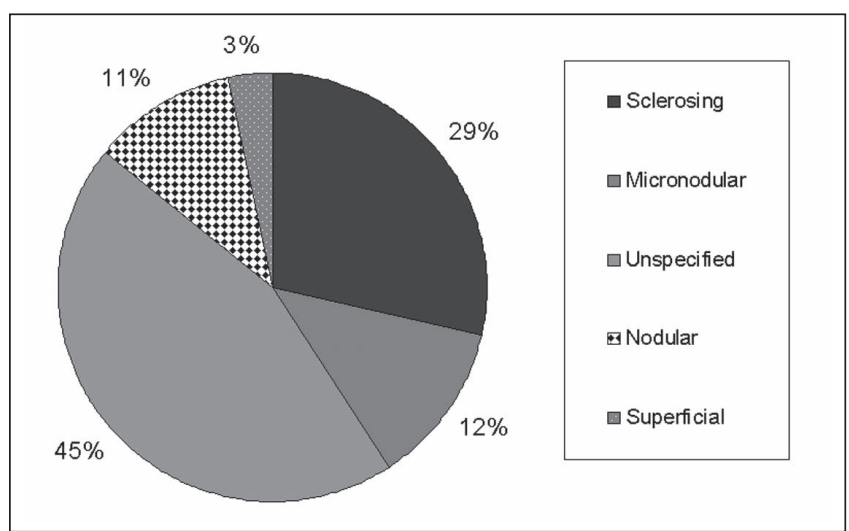

Figure 4) Histology of the 209 basal cell carcinomas included in the study

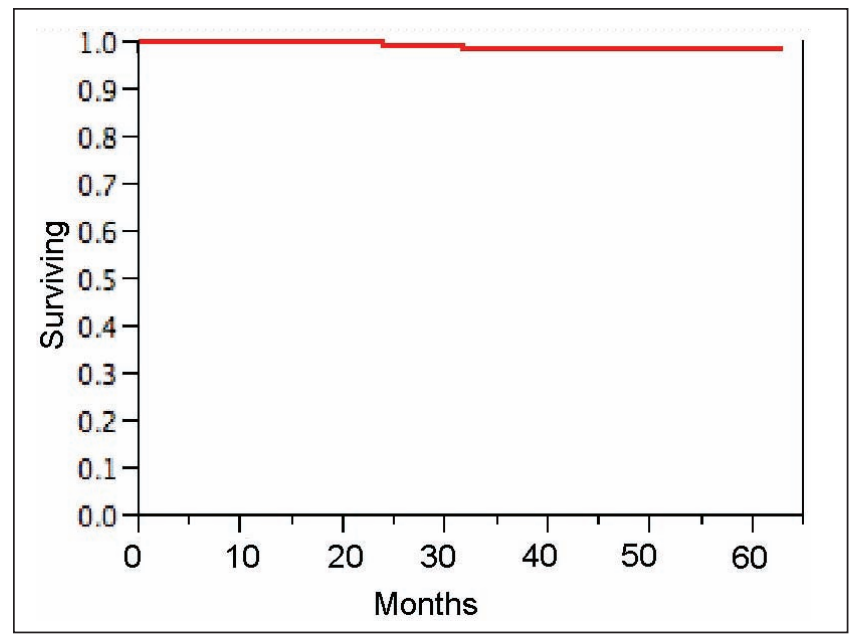

Figure 5) Kaplan-Meier survival curve demonstrating $98.5 \%$ recurrencefree survival at five years

an average of $28 \mathrm{~min}$. A mean operative time of $130 \mathrm{~min}$ was seen for traditional preparation, and $102 \mathrm{~min}$ for the new preparation $(\mathrm{P}=0.004)$. Note that the new and traditional specimen preparation groups were similar in terms of the number of previous recurrences (29\% versus $30 \%$; $\mathrm{P}=1.00)$, defect size $\left(3.7 \mathrm{~cm}^{2}\right.$ versus $\left.4.0 \mathrm{~cm}^{2} ; \mathrm{P}=0.81\right)$ and the number of levels required ( 1.9 versus $1.5 ; \mathrm{P}=0.05)$.

\section{DISCUSSION}

MMS is reserved for challenging tumours with aggressive histology located in difficult anatomical sites. Many of these lesions have undergone previous attempts at excision with positive margins before referral to the senior author (CT) for MMS. To optimize frozen specimen preparation, our group developed a simple, single-step system to provide rapid, accurate, full-face frozen sections. The technique has been previously published and its successful application is reported herein (1).

The lesions treated in the present series were challenging. Many of the basal cell carcinomas were of aggressive histological subtypes (sclerosing or micronodular). These lesions were large, such that an average of two levels and four blocks were required to achieve clear margins, with a maximum of 23 blocks. The resultant defects were large, with an average size of $3.68 \mathrm{~cm}^{2}$ and a maximum size of $50.04 \mathrm{~cm}^{2}$.

MMS is ideal for these types of tumours. The ability of MMS to review $100 \%$ of the tumour margin en face is ideal for cutaneous malignancies with aggressive features, which can be deceptively larger
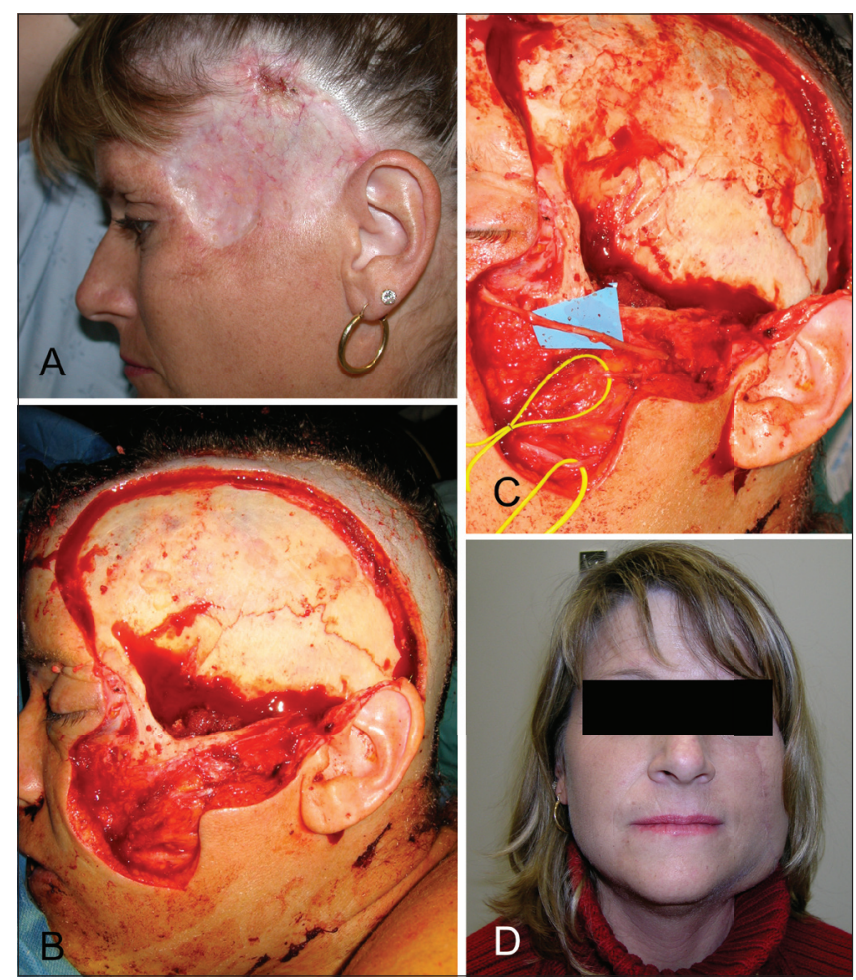

Figure 6) A A 42-year-old woman was referred for Mohs micrographic surgery with multiple, recurrent, radiated sclerosing basal cell carcinoma on the left temple. B Defect following Mohs micrographic surgery, with four levels and 23 blocks required to achieve clear margins. C Nerve graft for zygomatic branch of the facial nerve. Superficial temporal artery and vein were prepared for free latissimus dorsi flap reconstruction. D Patient shown at five months following reconstruction, before flap debulking

than they first appear. The benefit of obtaining complete tumour resection with minimal sacrifice of normal tissue cannot be overstated because these lesions are located on the face and are immediately adjacent to critical anatomical structures. The fact that complete margin evaluation is conducted at the time of resection ensures that there will be no surprise positive margins discovered on permanent section, and hence no re-resection of complex flap reconstructions. Not having to revise margins once MMS is complete is critical in these cases, which required flaps $78 \%$ of the time.

The operative times were significantly shorter using the new system than with conventional specimen preparation (102 min versus $130 \mathrm{~min} ; \mathrm{P}=0.004)$. This $28 \mathrm{~min}$ advantage is derived from three sources. First, the freezing platform of the new system is cooled to $-78^{\circ} \mathrm{C}$, which is much cooler than the standard cryostat temperatures of $-20^{\circ} \mathrm{C}$, allowing the TFC to freeze more quickly. Second, the single-step chuck/mold joining produces a consistently reproducible, parallel relationship between the true tissue margin and the cutting plane of the microtome blade. With an accurate, one-time adjustment of the chuck holder, the block face will always be parallel to the cutting plane of the microtome. With these parallel planes aligned, and with the tissue being visible at the block face, full-face sections can often be obtained with less than 150 microns of trimming-in. Finally, the new system has the thermal inertia to freeze multiple blocks over several hours outside of the cryostat, leaving the cryostat dedicated to slide production. Together, they contribute to the speed of specimen preparation.

Our five-year recurrence-free survival was $98.5 \%$, which compares favourably with MMS series of similar aggressive lesions (5-8). MMS is an ideal technique for these aggressive recurrent tumours in sensitive anatomical sites. Using our new system allowed MMS to be 
conducted in the most efficient manner, combining the advantages of high-quality care with efficiency of care delivery.

\section{CONCLUSIONS}

This new system enables fast, accurate, full-face frozen section specimens that are ideal for MMS, but the speed, accuracy and quality of the frozen sections are demonstrated by faster operative times, and a low recurrence rate that compares favourably with other MMS series.

\section{REFERENCES}

1. Yardley N, Henderson C, Joseph M, Temple C. A freezing technique for base mold embedding of multiple block frozen sections. J Histotech 2007;30:23-6.

2. Shriner DL, McCoy DK, Goldberg DJ, Wagner RF Jr. Mohs micrographic surgery. J Am Acad Dermatol 1998;39:79-97.

3. Snow SN, Madjar DD Jr. Mohs surgery in the management of cutaneous malignancies. Clin Dermatol 2001;19:339-47.

4. Miller LJ, Argenyi ZB, Whitaker DC. The preparation of frozen sections for micrographic surgery. A review of current methodology. J Dermatol Surg Oncol 1993;19:1023-9.

5. Smeets NW, Kuijpers DI, Nelemans P, et al. Moh's micrographic surgery for treatment of basal cell carcinoma of the face - results of a
DISCLOSURES/CONFLICT OF INTEREST: A provisional patent application has been filed for the mold and freezing platform concepts described in the present technique.

NOTE: All patients gave informed consent for the use of photos and their medical records.

retrospective study and review of literature. Br J Dermatol 2004;151:141-7.

6. Roenigk RK, Ratz JL, Bailin PL. Trends in the presentation and treatment of basal cell carcinomas. J Dermatol Surg Oncol 1986;12:860-5.

7. Rowe DE, Carroll RJ, Day CL Jr. Prognostic factors for local recurrence, metastasis, and survival rates in sqaumous cell carcinoma of the skin, ear, and lip. Implications for treatment modality selection. J Am Acad Dermatol 1992;26:976-90.

8. Mosterd K, Krekels GA, Nieman FH, et al. Surgical excision versus Mohs' micrographic surgery for primary and recurrent basal-cell carcinoma of the face: A prospective randomized controlled trial with 5-years' follow-up. Lancet Oncol 2008;9:1119-20. 